\title{
Identification of the profile and perceptions of Brazilian dentists regarding the use of rotary and/or reciprocating instruments in endodontic treatment
}

\author{
Renata Pereira Georjutti, ${ }^{1}$ Fernanda Ladico Miura, ${ }^{2}$ Rodrigo Antônio de Faria, ${ }^{3}$ Alexandre Sigrist de Martin, ${ }^{1}$ Carlos Eduardo da Silveira Bueno ${ }^{1}$ \\ ${ }^{1}$ Department of Endodontics, São Leopoldo Mandic Dental Research Center, Campinas, SP, Brazil \\ ${ }^{2}$ Multiprofessional Resident in Oncology Care, Dentistry Course, Uberlândia Federal University, Uberlândia, MG, Brazil \\ ${ }^{3}$ Department of Endodontics, Dentistry Course, Triangle Center University, Uberlândia, MG, Brazil \\ - Conflicts of interest: none declared.
}

Abstract

Objective: the aim of this study was to establish the profile of dentists with respect to some characteristics in the use of systems and kinematics of instrumentation most used in Brazil for endodontic treatment. Material and Methods: an invitation to participate in the survey was sent digitally to 1,300 dentists from January-April 2016, distributed in the five regions of Brazil, using a service available at surveymonkey.com (Survey Monkey, Palo Alto, CA, USA). They were validated 1,143 with the option of free and informed consent. The data collected were divided into two groups, the first group being only general practioners group (CG Group) and the second group, dentists that did postgraduation in Endodontics (PE Group). Data were statistically analyzed using the Mann-Whitney and Likelihood Ratio ( $p<0.05$ ). Results: most dentists of the two groups reside in the Southeast region; Are of the female gender; Average age between 26 and 34 years and have a postgraduate degree. The most striking feature of the use of the reciprocating system was the reduction in working time. Conclusion: within the limitations of the present research, it was concluded that most dentists presented a similar profile regardless of whether or not they had a postgraduate course, since they do not use rotating or reciprocating systems exclusively, being Protaper Universal $\circledast$ and Reciproc $\circledast$ the most used, associate the systems with manual files and reuse the files of the systems. Keywords: Dentistry; Endodontics; Surveys and questionnaires; Root canal therapy.

\section{Introduction}

everal systems of nickel-titanium (Ni-Ti) instruments have been introduced in endodontics since the 1990s, with the goal of minimizing difficulties faced by clinicians during endodontic treatment. ${ }^{1}$ There are some types of automated instrumentation, among which we can mention the instrumentation with continuous rotational movement and the instrumentation with alternating rotational movement, which can be symmetrical / oscillatory or asymmetric / reciprocating. $^{2-3}$

Brazil is currently the country with the greatest number of dentists (19\%), and endodontics is the specialty with the second greatest number of professionals registered at the Brazilian Federal Dentistry Board, totaling 13.641 specialists up to $2015 .{ }^{4}$ Data on the profile of Brazilian dentists regarding the use of Ni-Ti rotary and reciprocating systems are scant and incomplete.

Studies on this subject could help address important issues raised by scientific publications and continuing education courses, and also provide insight for the assessment of problems faced by clinicians in their daily endodontic practice. ${ }^{5}$ Overall, there are few studies on how endodontists-specialists or otherwise-regard new concepts, new techniques and new endodontic instruments, and on how these advances have influenced their daily clinical practice and quality of life.

The objective of this work was to identify the profile of dentists in relation to the use of the most used instrumentation and kinematics systems in Brazil for endodontic treatment through a questionnaire.
Ample Size

The sample size was calculated using the method of Cohran. ${ }^{6}$ Based on a Type I error of 0.05 and a power of $80 \%$, a minimum total sample of 384 individuals was considered necessary to detect differences between the two groups studied according to statistical tests.

\section{Experimental Design}

The two groups were composed of dentists that performed endodontic treatment in their day-to-day clinical, having in the first group only general practioners (CG Group) and in the second group, dentists that did postgraduate studies in Endodontics (Group PE), specialization, master or doctorate. The questionnaires were distributed in all demographic regions of Brazil. The study included only dentists residing in Brazil, enrolled in the Federal Council of Dentistry (CFO), which use automated instruments (files) that perform rotational or reciprocating movements during endodontic treatment. Questionnaires answered by dentists that were not enrolled in the CFO at the time of the survey or returned incompletely filled out were excluded.

\section{Data Collection}

This research was approved by the Research Ethics Committee of the São Leopoldo Mandic Dental Research Center (Opinion $\mathrm{n}^{\circ}$. 1.431.608), Campinas, SP. An invitation with a link to the questionnaire was sent digitally via email, WhatsApp or social media to 1,300 dentists, distributed in the 5 regions of Brazil, using the service available at 
www.surveymonkey.com (SurveyMonkey, Palo Alto, CA, USA). A total of 1.143 completed questionnaires were obtained from professionals who verified the free and informed consent check box agreeing to participate in the study.

The questionnaire comprised 17 items addressing information about the routine and clinical conduct of dentists during endodontic treatment. Each question was formulated to ensure that the participant reported a single response. When one or more questions were left unanswered, an automatic warning prevented further completion. After completing the questionnaire, the participants could no longer access their answers (Figure 1).

\section{SEARCH QUESTIONNAIRE}

1- Do you have any postgraduate degrees in Endodontics? () Do not have () Specialization () Master( ) Doctorate () Postdoctoral

2- Region in which you live ( ) North ( ) Northeast ( ) Midwest ( ) Southeast ( ) South

\section{3- Gender ( ) Male ( ) Female}

4. Age

5. Do you only use the Rotary system of NiTi in all cases of endodontic treatment? ( ) Yes ( )No

6- Do you only use the Reciprocanting system in all cases of endodontic treatment? ( ) Yes ( )No

7- How long have you been using the rotary motion? ( ) Less than 6 months ( ) Between 6 months and 1 year ( ) Between 1 and 2 years ( ) More than 2 years ago ( ) Never used

8- How long have you used the reciprocating movement? ( ) Less than 6 months ( ) Between 6 months and 1 year ( ) Between 1 and 2 years ( ) More than 2 years ago ( ) Never used

9. When you use rotating systems, do you interleave the channels with manual files? () I use only rotary NiTi instruments () I use rotating $\mathrm{NiTi}_{\mathrm{i}}$ instruments interleaving with hand instruments ( ) I never use this system

10- When you use reciprocating systemx, do you interleave the channels with manual files? () I use only reciprocating instruments ( ) I use reciprocating instruments interleaving with hand instruments ( ) Inever use this system

11- Which system(s) do you use frequently in your daily work? ( ) Prodesign S ( ) Protaper Next ( ) Mtwo ( ) Protaper Universal

( ) Prodesign R( )Reciproc ( ) Waveone ( ) TF Adaptive ( ) Biorace ( ) Hyflex ( ) Other

12- On average how many times do you reuse NiTi rotary instruments? ( ) Single use ( ) From 1 to 3 times ( ) From 3 to 6 times ( ) From 7 to 12 times ( ) Over 12 times ( ) Do not use rotating files

13- On average how many times do you re-use reciprocating instruments? ( ) Single use ()From 1 to 3 times ( ) From 3 to 6 times ( ) From 7 to 12 times ( ) Over 12 times ( ) I do not use reciprocating files

14- What is your preference for instrumentation in atresic channels? ( ) Manual ( ) Rotatory ( ) Reciprocating ( ) Hybridization

15. Do you have patency in all cases? ( ) Yes, in all ( ) No, I do not do it. ( ) Only in some cases regardless of the pulp condition.

( ) Only in cases of biopulpectony ( ) only in cases of pulp necrosis

16- Do foraminal enlargement in all cases? ( ) Yes, in all ( ) No, I do not do it. ( ) Only in some cases regardless of the pulp condition. ( ) Only in cases of biopulpectony ( ) only in cases of pulp necrosis

17- Which of the following characteristics do you personally believe to be the most outstanding in the use of Reciprocating instruments in your daily work? Check only one altemative. ( ) Reduced their costs ( ) Improved their technique in the treatment of root canals ( ) Less leaming curve ( ) Decreased preparation time and root canal filling ( ) I do not observe advantages ( ) I never use this system

Figure 1. The questionnaire comprised 17 items addressing information about the routine and clinical conduct of dentists during endodontic treatment 


\section{Statistical Analysis}

The data were tabulated in a digital spreadsheet (Microsoft Excel 2013, Richmond, VA, USA). The statistical analysis was performed using the Statistical Package for Social Sciences, version 23.0 (SPSS Inc., Chicago, IL, USA). The Mann-Whitney test was used to evaluate the difference between the two groups (CG Group e PE Group), and the likelihood ratio test was applied to evaluate the variables of region, gender, time elapsed since graduation, postgraduate studies in Endodontics, instrumentation system, technique and instrument used. The level of significance was set at $\mathrm{p}<0.05$.

\section{Results}

In the present study, 1,143 dentists completed the questionnaire correctly, corresponding to a response rate of $82.9 \%$. Of the total number of participants, $48.91 \%$ were located in the Southeast ( $\mathrm{p}<0.05), 8.22 \%$ in the Northeast,
$15.66 \%$ in the South, $9.62 \%$ in the Midwest and $17.59 \%$ in the North of the country. The majority were female $(60.72 \%$, $\mathrm{p}<0.05)$ and held a postgraduation in Endodontics $(82.24 \%$, $\mathrm{p}<0.05)$. In regard to the time elapsed since graduation, the category most represented was 3-4 years $(15.75 \%, p<0.05)$.

Regarding the use of instrumentation systems, the minority of the dentists reported using rotational systems exclusively during endodontic treatment, independent of the group ( $\mathrm{p}=0.005), 27.20 \%$ in the PE group and $17.70 \%$ in the group CG. The same was reported for reciprocating systems, the minority makes exclusive use of them ( $\mathrm{p}=$ 0.005), both in the PE group (11.10\%) and in the CG group (18.30\%).

Table 1 describes the most used instrumentation systems. In relation to the rotary instruments, in the two groups, the most important was the Protaper Universal (Dentsply Maillefer, Ballaigues, Switzerland) system and reciprocating were the Reciproc files (VDW, Munich, Germany).

Table 1. Frequencies and percentages of use of the systems and brands studied

\begin{tabular}{|c|c|c|c|c|c|c|}
\hline \multirow{3}{*}{ Variable } & \multirow{3}{*}{ Category } & \multicolumn{4}{|c|}{ POSTGRADUATION } & \multirow{3}{*}{ p-value } \\
\hline & & \multicolumn{2}{|c|}{ Yes (PE) } & \multicolumn{2}{|c|}{ No (CG) } & \\
\hline & & Freq. & $\%$ & Freq. & $\%$ & \\
\hline \multirow{2}{*}{ Rotary system only } & No & 684 & $72.80 \%$ & 167 & $82.30 \%$ & \multirow{2}{*}{0.005} \\
\hline & Yes & 256 & $27.20 \%$ & 36 & $17.70 \%$ & \\
\hline \multirow{2}{*}{ Reciprocating system only } & No & 834 & $88.90 \%$ & 165 & $81.70 \%$ & \multirow{2}{*}{0.005} \\
\hline & Yes & 104 & $11.10 \%$ & 37 & $18.30 \%$ & \\
\hline \multirow{2}{*}{ Prodesign S } & Yes & 341 & $36.30 \%$ & 54 & $26.60 \%$ & \multirow{2}{*}{0.009} \\
\hline & No & 599 & $63.70 \%$ & 149 & $73.40 \%$ & \\
\hline \multirow{2}{*}{ ProTaper Next } & Yes & 225 & $23.90 \%$ & 44 & $21.70 \%$ & \multirow{2}{*}{0.491} \\
\hline & No & 715 & $76.10 \%$ & 159 & $78.30 \%$ & \\
\hline \multirow{2}{*}{ Mtwo } & Yes & 314 & $33.40 \%$ & 60 & $29.60 \%$ & \multirow{2}{*}{0.289} \\
\hline & No & 626 & $66.60 \%$ & 143 & $70.40 \%$ & \\
\hline \multirow{2}{*}{ ProTaper Universal } & Yes & 395 & $42.00 \%$ & 81 & $39.90 \%$ & \multirow{2}{*}{0.578} \\
\hline & No & 545 & $58.00 \%$ & 122 & $60.10 \%$ & \\
\hline \multirow{2}{*}{ Prodesign $\mathrm{R}$} & Yes & 173 & $18.40 \%$ & 32 & $15.80 \%$ & \multirow{2}{*}{0.374} \\
\hline & No & 767 & $81.60 \%$ & 171 & $84.20 \%$ & \\
\hline \multirow{2}{*}{ WaveOne } & Yes & 326 & $34.70 \%$ & 68 & $33.50 \%$ & \multirow{2}{*}{0.748} \\
\hline & No & 614 & $65.30 \%$ & 135 & $66.50 \%$ & \\
\hline \multirow{2}{*}{ Reciproc } & Yes & 500 & $53.20 \%$ & 116 & $57.10 \%$ & \multirow{2}{*}{0.306} \\
\hline & No & 440 & $46.80 \%$ & 87 & $42.90 \%$ & \\
\hline \multirow{2}{*}{ Adaptive } & Yes & 53 & $5.60 \%$ & 8 & $3.90 \%$ & \multirow{2}{*}{0.329} \\
\hline & No & 887 & $94.40 \%$ & 195 & $96.10 \%$ & \\
\hline \multirow{2}{*}{ Biorace } & Yes & 99 & $10.50 \%$ & 6 & $3.00 \%$ & \multirow{2}{*}{0.001} \\
\hline & No & 841 & $89.50 \%$ & 197 & $97.00 \%$ & \\
\hline \multirow{2}{*}{ Hyflex } & Yes & 107 & $11.40 \%$ & 20 & $9.90 \%$ & \multirow{2}{*}{0.529} \\
\hline & No & 833 & $88.60 \%$ & 183 & $90.10 \%$ & \\
\hline \multirow{2}{*}{ Other (please specify) } & Yes & 201 & $21.40 \%$ & 30 & $14.80 \%$ & 034 \\
\hline & No & 739 & $78.60 \%$ & 173 & $85.20 \%$ & 0.034 \\
\hline
\end{tabular}


Regarding the time of use, it was observed that the two systems were used $(\mathrm{p}=0.001)$ for more than two years on the dentists of the PE group (71.40\% rotatory and $32.70 \%$ reciprocating) and less than six months (31\% rotational and $34.70 \%$ reciprocating). The association between rotations and manual files was reported by $82.20 \%$ of the dentists of the PE group and $74.30 \%$ of the CG group ( $\mathrm{p}=0.001$ ), whereas the association between reciprocanting and manual files was declared by $76.80 \%$ of the dentists of the PE group and $73.80 \%$ of the CG group ( $\mathrm{p}=0.001)$ (Table 2).
The hybridization of systems was considered when two or more techniques were associated (manual technique, rotary and reciprocating). The frequencies and percentages of instrumentation system hybridization are shown in.

Most dentists used Ni-Ti rotary instruments to treat 3 to 6 cases ( $p<0.05$ ), whereas most used reciprocating instruments to treat 1 to 3 cases $(p<0.05)$. The frequencies and percentages of instrumentation system reuse are presented in Table 3.

Table 2. Frequencies and percentages of system hybridization

\begin{tabular}{|c|c|c|c|c|c|c|}
\hline \multirow{3}{*}{ Variable } & \multirow{3}{*}{ Category } & \multicolumn{4}{|c|}{ POSTGRADUATION } & \multirow{3}{*}{ p-value } \\
\hline & & \multicolumn{2}{|c|}{ Yes (PE) } & \multicolumn{2}{|c|}{ No (CG) } & \\
\hline & & Freq. & $\%$ & Freq. & $\%$ & \\
\hline \multirow{4}{*}{ Rotary instrument hybridization } & $\begin{array}{l}\text { Sometimes I use only one system, other times I } \\
\text { hybridize }\end{array}$ & 324 & $34.50 \%$ & 52 & $25.60 \%$ & \multirow{4}{*}{0.001} \\
\hline & I never use this system & 42 & $4.50 \%$ & 20 & $9.90 \%$ & \\
\hline & I use only one system & 170 & $18.10 \%$ & 50 & $24.60 \%$ & \\
\hline & I use more than one system (hybridizes) & 404 & $43.00 \%$ & 81 & $39.90 \%$ & \\
\hline \multirow{4}{*}{$\begin{array}{l}\text { Reciprocating instrument hy- } \\
\text { bridization }\end{array}$} & $\begin{array}{l}\text { Sometimes I use only one system, other times I } \\
\text { hybridize }\end{array}$ & 250 & $26.70 \%$ & 52 & $25.60 \%$ & \multirow{4}{*}{0.262} \\
\hline & I never use this system & 101 & $10.80 \%$ & 25 & $12.30 \%$ & \\
\hline & I use only one system & 195 & $20.80 \%$ & 53 & $26.10 \%$ & \\
\hline & I use more than one system (hybridizes) & 392 & $41.80 \%$ & 73 & $36.00 \%$ & \\
\hline \multirow{3}{*}{ Rotary system alternation } & I never use this system & 42 & $4.50 \%$ & 24 & $11.90 \%$ & \multirow{3}{*}{$<0.001$} \\
\hline & I use only rotary $\mathrm{Ni}$-Ti instruments & 125 & $13.30 \%$ & 28 & $13.90 \%$ & \\
\hline & $\begin{array}{l}\text { I use rotary Ni-Ti instruments alternating with } \\
\text { hand instruments }\end{array}$ & 773 & $82.20 \%$ & 150 & $74.30 \%$ & \\
\hline \multirow{3}{*}{ Reciprocating system alternation } & I never use this system & 101 & $10.70 \%$ & 27 & $13.40 \%$ & \multirow{3}{*}{0.199} \\
\hline & I use only reciprocating instruments & 117 & $12.40 \%$ & 26 & $12.90 \%$ & \\
\hline & $\begin{array}{l}\text { I use reciprocating instruments alternating with } \\
\text { hand instruments }\end{array}$ & 722 & $76.80 \%$ & 149 & $73.80 \%$ & \\
\hline
\end{tabular}

Table 3. Frequency and percentages of reuse of systems

\begin{tabular}{|c|c|c|c|c|c|c|}
\hline \multirow{3}{*}{ Variable } & \multirow{3}{*}{ Category } & \multicolumn{4}{|c|}{ POSTGRADUATION } & \multirow{3}{*}{ p-value } \\
\hline & & \multicolumn{2}{|c|}{ Yes (PE) } & \multicolumn{2}{|c|}{ No (CG) } & \\
\hline & & Freq. & $\%$ & Freq. & $\%$ & \\
\hline \multirow{7}{*}{ Reuse of rotary instruments } & $12+$ times & 18 & $1.90 \%$ & 5 & $2.50 \%$ & \multirow{7}{*}{$<0.05$} \\
\hline & 1 to 3 times & 251 & $26.70 \%$ & 67 & $33.00 \%$ & \\
\hline & 3 to 6 times & 468 & $49.80 \%$ & 89 & $43.80 \%$ & \\
\hline & 7 to 12 times & 140 & $14.90 \%$ & 15 & $7.40 \%$ & \\
\hline & I do not use Ni-Ti rotary files & 30 & $3.20 \%$ & 13 & $6.40 \%$ & \\
\hline & I never use this system & 15 & $1.60 \%$ & 6 & $3.00 \%$ & \\
\hline & Single use & 18 & $1.90 \%$ & 8 & $3.90 \%$ & \\
\hline \multirow{7}{*}{$\begin{array}{l}\text { Reuse of reciprocating instru- } \\
\text { ments }\end{array}$} & $12+$ times & 6 & $0.60 \%$ & 0 & $0.00 \%$ & \multirow{7}{*}{0.05} \\
\hline & 1 to 3 times & 411 & $43.70 \%$ & 93 & $45.80 \%$ & \\
\hline & 3 to 6 times & 237 & $25.20 \%$ & 55 & $27.10 \%$ & \\
\hline & 7 to 12 times & 45 & $4.80 \%$ & 3 & $1.50 \%$ & \\
\hline & $\begin{array}{l}\text { I do not use reciprocation or other asymmetric } \\
\text { oscillatory motion }\end{array}$ & 99 & $10.50 \%$ & 27 & $13.30 \%$ & \\
\hline & I never use this system & 3 & $0.30 \%$ & 1 & $0.50 \%$ & \\
\hline & Single use & 139 & $14.80 \%$ & 24 & $11.80 \%$ & \\
\hline
\end{tabular}


Figure 2 shows the data referring to the two groups evaluated regarding the preference of instrumentation adopted in atresic channels, the performance of patency, realization of foraminal magnification and the motive of the preference of those who make use of reciprocating movement.

A

Motion used for constricted canals

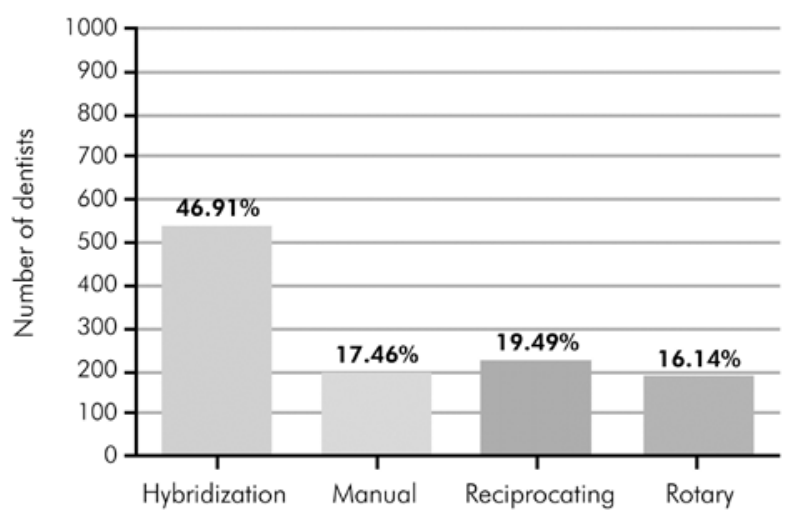

C Foraminal enlargement

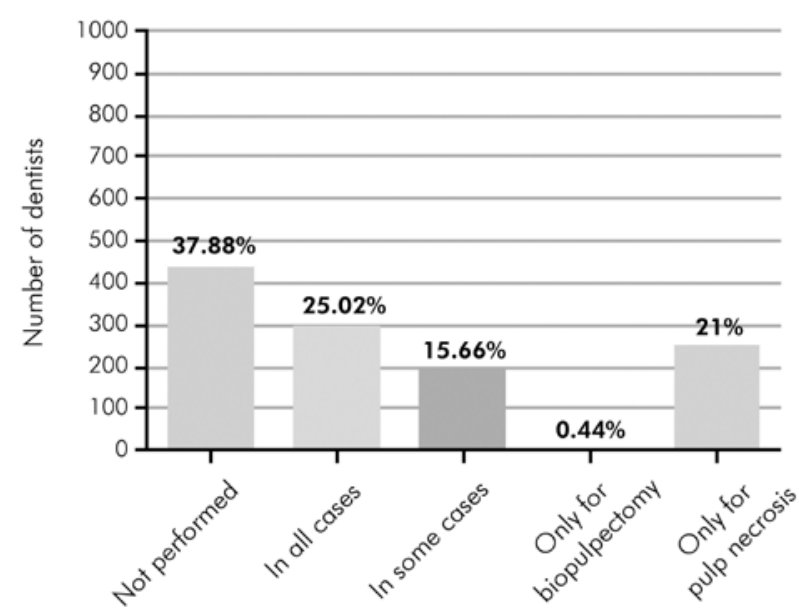

naires sent (1.300) was higher than the previous study and 1.143 were duly answered, a number that corresponds to a valid representation of the dentist users of rotating and reciprocating systems in Brazil.



D Perceptions during use of reciprocating systems

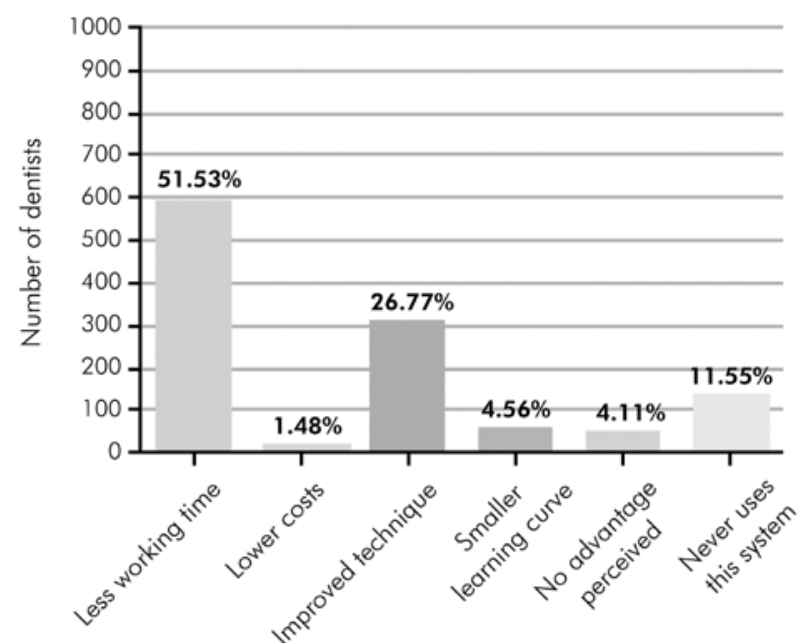

Figure 2. (A) Motion used by dentists for constricted canals. (B) Obtaining of foraminal patency in clinical practice by dentists. (C) Performing of foraminal enlargement in clinical practice by dentists. (D) Perceptions reported by the interviewees during the use of reciprocating systems. Different letters indicate statistical difference $(p<0.05)$

\section{Discussion}

The survey should be based on the mean repetition of the responses, with a representative sample size, both in the pilot phase and in the validation phase of the data. ${ }^{7}$ In several studies using questionnaires, the minimum average of valid responses, that is, for global response rates to be considered representative, is in the range of $75-80 \% .^{8-9}$ This is consistent with that obtained in the present study (82.9\%) and higher than those found in previous studies. ${ }^{5,10-12}$

One important limitation highlighted in the study, ${ }^{9}$ was the number of questionnaires that were duly answered, since a total of 290 questionnaires answered in their study may not correspond to a representative number in the region studied. In the present study, the number of question-
Most of the respondent dentists are located in the Southeast region of Brazil (48.91\%). This data confirms those reported in previous studies regarding the unequal geographic distribution of professionals in the country, with a greater presence of dental surgeons in the states of the Southeast region and in the state of São Paulo (27.7\%). ${ }^{13-14}$

In the present study, the majority of the interviewees, independent of the group, were female $(60.72 \%)$, had a postgraduate degree (82.24\%), worked as a general practioners and had a mean age between 26 and 34 years. Another study13 also found a majority of females (58.7\%) among the interviewed dentists, but the mean age was higher (43.1 years). Result different from those found, ${ }^{15}$ in which $53 \%$ of the respondents of the 799 questionnaires to the National 
Health Service of six districts were male, and only 5\% reported having a postgraduate degree in Endodontics. The same was observed in a study conducted in West India where most of the 290 interviewees were general practitioners ( $\mathrm{n}=$ 173) and the minority had some type of postgraduate (42 endodontists and 75 with other specializations). 9 These differences can be explained by the fact that the surveys were carried out in places with different realities.

Previous studies have found that the average length of dentists in London was 16 years ${ }^{15}$ and in Brazil 10.6 years. ${ }^{13}$ In the present study, the only graduated dentists were formed between 6 months and 2 years, while those who had a graduate course were formed more than 4 years ago. As for instrumentation systems, satisfactory results have been obtained both in the use of the rotational system, in which different instruments are used sequentially, and in that of reciprocating systems, 16 such as WaveOne (Dentsply Maillefer) and Reciproc (VDW). ${ }^{17-18}$ These instruments are considered suitable for the preparation of root canals with alternating rotation kinematics. ${ }^{19}$ However, the use of different systems in the same treatment has been suggested with the aim of carrying out preparations without deviations or other complications. ${ }^{20-21}$

A previous study, ${ }^{22}$ with the aid of a questionnaire, showed that the most frequently used Ni-Ti instruments were those of the Profile system (Dentsply Maillefer) (39.8\%), followed by the ProTaper Universal (Dentsply Maillefer). These data contrast with those of the present study, in which the most used rotary systems were Protaper Universal, Predesign S and Mtwo, regardless of whether the dentists had or not undergraduate Endodontics. This fact can be justified by the time elapsed between the moments of the two studies and the modification of the techniques, considering that the techniques and instruments are influenced by recent research, opinions of leaders, postgraduate training, continuing education and product marketing. ${ }^{5,23}$

Regarding the time that the interviewees used the instrumentation systems important differences were observed between the groups. The fact that the dentist has a postgraduate degree in Endodontics (PE group) increased the time of use in a year and a half, both of the rotating systems as well as the reciprocating. This fact can be explained by the PE group being formed by more experienced people, who dominate more techniques and had more time to dedicate themselves to the study.

A common practice among dentists that work with automated systems is the reuse of the instruments in a number of cases. In another job ${ }^{22}$ observed that the majority of respondents (54.3\%) reused Ni-Ti files more than 10 times, with $54.6 \%$ of them responding that limb fracture occurred less than 5 times a year. In the United Kingdom, $44.8 \%$ of dentists reported discarding rotary instruments after first use. ${ }^{24}$ In the present study, the two groups reported reusing rotational systems between 3 and 6 times and reciprocating between 1 and 3 times. Considering that the majority of the interviewees did not reuse the systems more than six times, a trend of lower fracture risk was observed, since the num- ber of fractures is associated with the number of channels treated. ${ }^{24}$

$\mathrm{Ni}-\mathrm{Ti}$ instruments generally fractured when used eight or more times, and the amount of fracture observed when using only the rotational technique is greater than when hybridizing the rotational system with manual files. ${ }^{25} \mathrm{Sev}-$ eral studies have observed that the instruments used with alternating rotation have a greater average number of uses compared to the ones with continuous rotation. ${ }^{26}$

Even with all this technological evolution, the anatomical variations of the root canals remain a challenge to obtain the conformation and cleaning of the root canal system. There is as yet no instrument or instrumental system that fully achieves these objectives, particularly in the apical portion and in the isthmus zones between channels. ${ }^{21}$ Hybridization of some instrumentation systems can be performed without significantly interfering with the original root canal morphology and obtaining a higher degree of cleaning than when a single system is used. The hybridization of instrumentation techniques is also a common practice reported between the dentists of the present study. Most clinicians and endodontists (more than 70\%) intercalate the use of rotary or reciprocating instruments with manual files, especially in cases of atresic channels.

In a study that had the aid of a questionnaire to verify the use of Ni-Ti rotary instruments by endodontists in the state of Rio Grande do Sul, the greatest advantages reported by professionals were the rapidity of preparation of root canals and the lower stress of the patient and of the professional when compared to the one generated during the application of manual instrumentation techniques. ${ }^{27}$ Single-file instrumentation has also demonstrated the advantage of being faster in the studies. ${ }^{28}$ In the present study, the characteristics of the alternating (reciprocating) rotation systems most reported by the dentists (of the two groups) were the reduction in preparation and filling time of the canals, followed by improvement in the technique in endodontic treatment.

The achievement of foraminal patency and foraminal enlargement was another issue addressed in the present study. The patency procedure, during endodontic treatment, prevents the accumulation of dentin scrapings that may compromise the preparation of the apical third. ${ }^{29,30}$ In addition to avoiding deviations or losses of the work limit, but especially in infected canals, it interferes with the microbial arrangement in the apical foramen; Promoting an imbalance and reduction of bacterial aggressiveness and, therefore, inducing a biological response, most of the times, positive..$^{30,31}$ The foraminal patency was reported to be obtained in all cases by $81.20 \%$ of the dentists interviewed in the PE group and $70.9 \%$ in the CG group, whereas the foraminal enlargement has not been performed by a large part of the interviewees (between 36, 90\% and 42.40\%). This fact may be due to the greater amount of apical extrusion of the shutter material that occurs when the magnification is made during instrumentation. ${ }^{32}$ However, the smaller amount of debris accumulated with both alternating and continuous rotating instruments should be taken into account when performing 
foraminal magnification. ${ }^{33}$

The present study allowed the approach of an expressive number of dentists $(n=1,143)$, a fact that is mainly due to the ease of access of the participants to the questionnaire. On the other hand, the fact that the study was based on the application of a questionnaire can be considered a limitation, since a direct observation of the procedures performed by the participating dentists was not performed.

In conclusion, the data of this research indicate that the majority of Brazilian dentists are located in the Southeast, are women, with postgraduation in Endodontics. Regarding the use of instrumentation systems, most dental surgeons presented a similar profile regardless of whether or not they had a postgraduate course, do not make use of rotary or reciprocating systems, and the Protaper Universal and Reciproc systems are the most used. They associate systems with manual files, reuse systems files, perform foraminal patency in most cases and are not adept at foraminal enlargement.

\section{References}

1. Celik D, Tasdemir T, Er K. Comparative study of 6 rotary nickel-titanium systems and hand instrumentation for root canal preparation in severely curved root canals of extracted teeth. J Endod. 2013;39(2):278-82.

2. Kim HC, Kwak SW, Cheung GSP, Ko DH, Chung SM, Lee W. Cyclic Fatigue and Torsional Resistance of Two New Nickel-Titanium Instruments Used in Reciprocation Motion: Reciproc Versus WaveOne. J Endod. 2012;38(4):541-4.

3. Pereira ES, Peixoto IF, Viana AC, Oliveira II, Gonzalez BM, Buono VT, et al. Physical and mechanical properties of a thermomechanically treated NiTi wire used in the manufacture of rotary endodontic instruments. Int Endod. 2012;45(5):469-74. 4. Morita MC, Haddad AE, Araújo ME. Perfil Atual e Tendência do Cirurgião-Dentista Brasileiro. Maringá: Dental Press; 2010.

5. Bird DC, Chambers D, Peters OA. Usage parameters of nickel-titanium rotary instruments: a survey of endodontists in the United States. J Endod. 2009;35(9):11937.

6. Cochran, W. Sampling Techniques, 3rd ed. New York: John Wiley \& Sons; 1986. 7. Lydeard S. The questionnaire as a research tool. Fam Pract. 1991;8(1):84-91.

8. Parashos P, Messer HH. Questionnaire survey on the use of rotary nickel-titanium endodontic instruments by Australian dentists. Int Endod J. 2004;37(4):249-59. 9. Jadhav GR, Mittal P. Anaesthesia Techniques for Maxillary Molars - A Questionnaire-Based Retrospective Field Survey of Dentist in Western India. J Clin Diagn. 2016;10(3):15-7.

10. Dutner J, Mines P, Anderson A. Irrigation trends among American Association of Endodontists members: a web-based survey. J Endod. 2012;38(1):37-40.

11. Crawford FJ, McQuistan RM, Williamson EA, Qian F, Potter SK. Should endodontists place dental implants? A national survey of general dentists. J Endod. 2011;37(10):1365-9.

12. Azarpazhooh A, Dao T, Figueiredo R, Krahn M, Friedman S. A survey of dentists' preferences for the treatment of teeth with apical periodontitis. J Endod. 2013;39(10):1226-33.

13. Arouca R, Pereira HC, Alves LC. Demographic census of the workforce in dental specialties [in Portuguese]. v. 1. Rio de Janeiro: ENSP/Fiocruz; 2010.

14. Mathias MP, Casani E, Sagaz SM, Lucietto DA. Dentists and dental schools in Brazil: repercussions on dental practice. J Oral Invest. 2015;4(2):25-31.

15. Ghotane SG, Al-Haboubi M, Kendall N, Robertson C, Gallagher JE. Dentists with enhanced skills (Special Interest) in Endodontics: gatekeepers views in London. BMC Oral Health. 2015;15(1):110.

16. Grande NM, Ahmed AMH, Cohen S, Bukiet F, Plotino G. Current Assessment of Reciprocation in Endodontic Preparation: A Comprehensive Review - Part I: Historic Perspectives and Current Applications. J Endod. 2015;41(11):1778-83.

17. Gambarini G, Gergi R, Naaman A, Osta N, Al Sudani D. Cyclic fatigue of twisted file rotary Niti instruments used in reciprocating motion. Int Endod J. 2012;45(9):802-6.

18. Capar ID, Ertas H, Ok E, Arslan H, Ertas ET. Comparative study of different novel nickel-titanium rotary systems for root canal preparation in severely curved root canals. J Endod. 2014;40(6):852-6.

19. Plotino G, Ahmed HM, Grande NM, Cohen S, Bukiet F. Current assessment of reciprocation in endodontic preparation: a comprehensive review--part II: properties and effectiveness. J Endod. 2015;41(12):1939-50.

20. Piotto LD, Alfredo SC, Fernando GA, Mariane SC, Sens FTF, Baratto-Filho F. Influence of prior cervical enlargement on apical cleaning using single file. Bull Tokyo Dent Coll. 2015;56(2):85-91.

21. Capar ID, Arslan H. A review of instrumentation kinematics of enginedriven nickel-titanium instruments. Int Endod J. 2016;49(2):119-35.

22. Lee W, Song M, Kim E, Lee H, Kim HC. A survey of experience-based preference of Nickel-Titanium rotary files and incidence of fracture among general dentists. Restor Dent Endod. 2012;37(4):201-6.

23. Shen Y, Zhou HM, Zheng YF, Peng B, Haapasalo M. Current challenges and concepts of the thermomechanical treatment of nickel-titanium instruments. J Endod. 2013;39(2):163-72.

24. Madarati AA, Watts DC, Qualtrough AJ. Opinions and attitudes of endodontists and general dental practitioners in the UK towards the intracanal fracture of endodontic instruments: part 1. Int Endod J. 2008;41(12):693-701.

25. Farid H, Khan FR, Rahman M. ProTaper rotary instrument fracture during root canal preparation: a comparison between rotary and hybrid techniques. Oral Health Dent Manag. 2013;12(1):50-5.

26. Ahn SY; Kim HC; Kim E. Kinematic effects of nickel-titanium instruments with reciprocating or continuous rotation motion: a systematic review of in vitro studies. J Endod. 2016;42(7):1009-17.

27. Zenkner CLL, Paglarin CL, Perez GP, Barletta FB. Use of nickel-titanium rotary instruments by endodontists from Rio Grande do Sul, Brazil [in Portuguese]. Dental Press Endod. 2011;1:45-51.

28. Paqué F, Zehnder M, De Deus G. Microtomography-based comparison of reciprocating Single-File F2 ProTaper technique versus rotary full sequence. J Endod. 2011;37(10):1394-7.

29. Borlina SC, Souza V, Holland R, Murata SS, Gomes-Filho JE, Dezan Junior E et al. Influence of apical foramen widening and sealer on the healing of chronic periapical lesions induced in dogs' teeth. Oral Surg Oral Med Oral Pathol Oral Radiol Endod. 2010;109(6):932-40.

30. Machado R, Ferrari CH, Back E, Comparin D, Tomazinho LF, Vansan LP. The impact of apical patency in the success of endodontic treatment of necrotic teeth with apical periodontitis: a brief review. Iran Endod J. 2016;11(1): 63-6.

31.Khatavkar R, Hegde VS. Importance of patency in endodontics. Endodontol. 2010;22(2):85-91.

32. Tinaz AC, Alacam T, Uzun O, Maden M, Kayaoglu G. The effect of disruption of apical constriction on periapical extrusion. J Endod. 2005;31(7):533-5.

33. De-Deus G, Marins J, Silva EJ, Souza E, Belladonna FG, Reis C, et al. Accumulated hard tissue debris produced during reciprocating and rotary nickel titanium canal preparation. J Endod. 2015;41(5):676-81.

\section{Mini Curriculum and Author's Contribution}

1. Renata Pereira Georjutti - DDS and MSc. Contribution: manuscript writing, experimental procedures, and manuscript review.

2. Fernanda Ladico Miura - DDS and MSc. Contribution: manuscript writing, experimental procedures, and manuscript review.

3. Rodrigo Antônio de Faria - DDS and MSc. Contribution: manuscript writing and manuscript review.

4. Alexandre Sigrist de Martin- DD and PhD. Contribution: manuscript writing and manuscript review.

5. Carlos Eduardo da Silveira Bueno - DDS and PhD. Contribution: manuscript writing, manuscript review, work supervisor and paper submission. 